\title{
Determination criterion of defrosting condition for variable refrigerant flow air conditioning system
}

\author{
Qiu Tu ${ }^{\mathrm{a}, \mathrm{b}, *}$, Jingqiang $\mathrm{Xu}^{\mathrm{a}, \mathrm{b}}$, Yuhai Feng ${ }^{\mathrm{c}}$, Shoubo Mao ${ }^{\mathrm{c}}$, Defang Guo ${ }^{\mathrm{c}}$, Jianqi $\mathrm{He}^{\mathrm{c}}$ \\ a Guangzhou Institute of Energy Conversion, Chinese Academy of Science, Guangzhou 510640, China \\ ${ }^{\mathrm{b}}$ Key Laboratory of Renewable Energy and Gas Hydrate, Chinese Academy of Science, Guangzhou 510640, China \\ ${ }^{\mathrm{c}}$ Haier Air-Conditioning Electronic Co. LTD., Qingdao 266510, China
}

\section{A R T I C L E I N F O}

\section{Article history:}

Received 7 September 2010

Received in revised form

27 December 2011

Accepted 9 January 2012

\section{Keywords:}

Defrosting

Defrosting condition

Condensation temperature

Defrosting cycle

Coil temperature

\begin{abstract}
A B S T R A C T
The disadvantage of the defrosting determination criterion of time-coil temperature was theoretically analyzed and experimentally verified. Considering the different characteristics of variable refrigerant flow air conditioning system (VRF AC) from the common air conditioners, the defrosting criterion model of time-coil temperature-condensation temperature has been built. In this model, there exist four temperature regions based on different frosting characteristics at different ambient temperatures, i.e., $T_{\mathrm{ao}}\left({ }^{\circ} \mathrm{C}\right) \in(-\infty,-9],(-9,0],(0,4],(4,21]$. The relations between the defrosting judgment temperatures and ambient temperatures have been determined by experiments. And the minimum defrosting cycle when $T_{\mathrm{ao}}\left({ }^{\circ} \mathrm{C}\right) \in(-9,21]$ and $T_{\mathrm{ao}}\left({ }^{\circ} \mathrm{C}\right) \in(-\infty,-9]$ were respectively determined to be $60 \mathrm{~min}$ and $90 \mathrm{~min}$ by experiments. Moreover, the defrosting accumulative coefficient, the defrosting judgment time constant and the restriction of the condensation temperature have been introduced into the model. Thus the complete criterion model can avoid delayed and premature defrosting, even false defrosting and inaccessible defrosting. A large number of experiments have verified the feasibility of the model.
\end{abstract}

(C) 2012 Elsevier B.V. All rights reserved.

\section{Introduction}

During heating operation at a certain ambient temperature and humidity, the air conditioning system absorbs heat from the outside cold air and discharges heat into the living space. When the surface temperature in the outdoor heat exchanger is below $0{ }^{\circ} \mathrm{C}$ and less than the dew point temperature of the moist air, vapor in the air will be condensed into frost layer and attached to the heat exchanger surface. With the growth of frost layer, fan motor current and heat transfer thermal resistance increase, subsequently, the air outlet temperature from indoor units and heat pump efficiency decrease. To avoid these problems, the accumulated frost must be timely removed from the heat exchanger surface by an effective defrosting style.

From the literature survey, large numbers of defrosting methods and control measures have been reported in the past, such as reverse-cycle defrosting [1-5], hot-gas bypass defrosting [5-9], refrigerant charge compensation defrosting [10] and throttled defrosting in sequences [11]. However, very few literatures are concerned on the determination criterion of defrosting condition.

\footnotetext{
* Corresponding author at: Guangzhou Institute of Energy Conversion, Chinese Academy of Science, Guangzhou 510640, China. Tel.: +86 2087211743 ; fax: +862087057795.

E-mail address: tuqiuky@163.com (Q.Tu).
}

Chen and $\mathrm{Li}$ [12] proposed the mathematical model of time and coil temperature change rate as defrosting determination criterion. The determination method is almost similar to the time-coil temperature determination criterion. Fang et al. [13] studied the optimal defrosting point of the constant temperature and humidity system under the constant outdoor temperature and humidity, variable indoor temperature and humidity situation. They thought that the ratio of the condensation pressure to the evaporation pressure can be set as the optimal defrosting point when the area of the frost covered the evaporator comes up to $75 \%$ of the heat-exchanging area of the evaporator. The method is not feasible for variable refrigerant flow air conditioning system (VRF AC) with EEVs due to its characteristics, either. For heating, the output capacity of the compressors is adjusted in accordance with a certain condensation temperature target, for example, $46^{\circ} \mathrm{C}$. When the required load increases to lead to enhancement of the compressor output capacity, the suction pressure decreases, subsequently the pressure ratio increases. Similarly, when the required load drops, the pressure ratio will decrease. Furthermore, the frost layer is almost evenly distributed on the surface of the heat exchanger, so it is very difficult to assess the proportion of occupied area of the heat exchanger. Therefore the pressure ratio cannot be used as the criterion of defrosting condition for VRF AC.

The determination criterion of defrosting condition is one of the key technologies for air conditioning systems, especially for VRF AC due to its complex construction and control measure [14-16], and 


\begin{tabular}{|c|c|}
\hline \multicolumn{2}{|c|}{ Nomenclature } \\
\hline EEVa1 & electric expansive valve in the outdoor unit (PLS) \\
\hline EEVa2 & electric expansive valve in the indoor unit (PLS) \\
\hline$f$ & defrosting cumulative coefficient \\
\hline INV_F & $\begin{array}{l}\text { running frequency of the inverter-driven compres- } \\
\text { sor }(\mathrm{Hz})\end{array}$ \\
\hline LEVa1 & opening of EEVa1 \\
\hline$P_{\mathrm{d}}$ & discharge pressure (bar) \\
\hline$P_{\mathrm{d}_{-} \mathrm{t}}$ & $\begin{array}{l}\text { saturation temperature corresponding to } P_{\mathrm{d}} \text {, } \\
\text { namely condensation temperature }\left({ }^{\circ} \mathrm{C}\right)\end{array}$ \\
\hline$P_{\mathrm{S}}$ & suction pressure (bar) \\
\hline$T_{\mathrm{ao}}$ & ambient temperature $\left({ }^{\circ} \mathrm{C}\right)$ \\
\hline$T_{\mathrm{c}, \mathrm{c}}$ & current condensation temperature $\left({ }^{\circ} \mathrm{C}\right)$ \\
\hline$T_{\mathrm{c}, \mathrm{tar}}$ & condensation temperature target $\left({ }^{\circ} \mathrm{C}\right)$ \\
\hline$T_{\mathrm{c} 1}$ & temperature in the gas pipe of the indoor unit $\left({ }^{\circ} \mathrm{C}\right)$ \\
\hline$T_{\mathrm{c} 2}$ & $\begin{array}{l}\text { throttled temperature in the liquid pipe of the } \\
\text { indoor unit }\left({ }^{\circ} \mathrm{C}\right)\end{array}$ \\
\hline$T_{\text {def }}$ & coil temperature $\left({ }^{\circ} \mathrm{C}\right)$ \\
\hline$T_{\mathrm{def}, X}$ & $\begin{array}{l}\text { defrosting judgment temperature }\left({ }^{\circ} \mathrm{C}\right) . X \text { represents } \\
\text { ambient temperature point or region, such as } A B \text {, } \\
\text { BO, O, OC, CD. }\end{array}$ \\
\hline$T_{\mathrm{di}}$ & $\begin{array}{l}\text { discharge temperature of the inverter-driven com- } \\
\text { pressor }\left({ }^{\circ} \mathrm{C}\right)\end{array}$ \\
\hline$T_{\mathrm{d} 1}$ & $\begin{array}{l}\text { discharge temperature of the standard compressor } \\
\left({ }^{\circ} \mathrm{C}\right)\end{array}$ \\
\hline$T_{\text {oil }}$ & compressor oil temperature $\left({ }^{\circ} \mathrm{C}\right)$ \\
\hline$t_{\mathrm{r}, X}$ & $\begin{array}{l}\text { Running time of the compressors timed by the first } \\
\text { calculagraph (min). } X \text { represents ambient tempera- } \\
\text { ture region, such as } \mathrm{AB}, \mathrm{BO}, \mathrm{OC}, \mathrm{CD}\end{array}$ \\
\hline$t_{\mathrm{d}, X}$ & $\begin{array}{l}\text { defrosting judgment time timed by the second cal- } \\
\text { culagraph (min) }\end{array}$ \\
\hline$t_{\text {con }}$ & $\begin{array}{l}\text { defrosting criterion time constant determined by } \\
\text { experiment (min) }\end{array}$ \\
\hline$\Delta t_{\mathrm{r}, \mathrm{CD}(\mathrm{E})}$ & $\begin{array}{l}\text { extended running time of the compressor timed by } \\
\text { the first calculagraph when } T_{\mathrm{ao}} \leq-9{ }^{\circ} \mathrm{C} \text { (min) }\end{array}$ \\
\hline
\end{tabular}

becomes an area of interest to designers. If the criterion is not accurate and complete, it will result in delayed or premature defrosting, even false defrosting and inaccessible defrosting. Delayed defrosting and inaccessible defrosting will lead to accumulate very thick frost layer around the heat exchanger surface, degrade heat transfer performance of the heat exchanger, and discharge little cool air from indoor units, even burn the fan motor due to excessive high motor current. On the other hand, premature defrosting and false defrosting will affect the application of VRF AC. Currently, several commonly used determination criterions are timed defrosting model, time-coil temperature method, model of temperature difference between evaporation temperature and ambient temperature, model of pressure difference between the inlet and outlet of the heat exchanger.

The time-coil temperature determination criterion is the most commonly used method in air condition systems. The control measure is that after running a certain time defined in the control program, the machine meets the defrosting condition and begins to defrost when the coil temperature is less than the set temperature. However, the accuracy of this determination criterion should still be improved, especially for VRF AC with electric expansive valves (EEVs). It can be explained as below. The suction pressure can make great influence on the coil temperature, i.e., the coil temperature decreases with drop of suction pressure, and easily meets the defrosting condition. As a complex multi-input and multi-output system, the variables in VRF AC are mutually coupled and any change in one variable will have an impact on the suction pressure, in which output ability of the compressors and opening of EEVs are the most main influence factors. For example, when the required load of indoor units lifts, the compressor output capacity increases accordingly. This will reduce suction pressure within a short time. In addition, the EEV of the outdoor unit is controlled by the discharge temperature overheating degree. When the overheating degree decreases, the opening of EEV results in lower suction pressure. Once the suction pressure decreases and leads to lower coil temperature accordingly, the defrosting determination condition can be easily met, and defrosting process will be carried out. But actually, it is false defrosting phenomenon because of no frost formed around the heat exchanger.

Similarly, the determination criterion of temperature difference between evaporation temperature and the ambient temperature also may lead to false defrosting due to the influence of the suction pressure.

Moreover, because the determination criterion of pressure difference between two sides of the heat exchangers increases the design cost of the machine due to adoption of two pressure sensors or one differential pressure sensor, and the pressure sensor(s) are not convenient to be installed, it has not been used in VRF AC, and its feasibility has not been tested by experiment.

Recently, Zhujun et al. [17] proposed the maximum average heating capacity as defrosting determination criterion. Taking into account the fact that in practical engineering application, the wet bulb temperature cannot be measured and the heating capacity cannot be calculated thereby, they considered that the approach can ignore the influence of air humidity on heating capacity, and there is no latent heat exchange, but only sensible heat exchange. Thus the heating capacity is approximately proportional to the air flow and temperature difference between air inlet temperature and air outlet temperature. However, for VRF AC, the status of dozens of indoor units cannot be the same simultaneously. For example, some indoor units are in standby status, but other indoor units are in heating motion. Thus the maximum heat capacity cannot be quantified. So this method cannot be used in practical applications, either.

Byun et al. [18] proposed the application of photo-coupler for frost detecting, which is efficient in automating the defrosting process due to its more exact detection ability for frost formation and elimination. However, the detecting style increases the cost of the machine. Currently, the technology has not yet applied in VRF AC.

In short, these above simple determination criterions except photo-coupler detecting method may bring out a lot of problems if they are used in VRF AC, such as delayed or premature defrosting, even false defrosting and inaccessible defrosting. In this paper, considering the different features of VRF AC from those of common air conditioners, the criterion model of time-coil temperaturecondensation temperature has been proposed to improve the control accuracy and avoid the defrosting problems because it takes into account the ambient temperature change and the coil temperature fluctuation caused by all kinds of factors, such as the resistance drift of coil temperature sensor, the opening regulation of EEV, required load change of indoor units, and so on. It is hoped that this study can provide help for designers in VRF AC and that it will stimulate further research on this topic.

\section{Experimental phenomenon and analysis}

\subsection{Introduction of $V R F A C$}

A system principle diagram of VRF AC is shown in Fig. 1, which is composed of an outdoor unit and 2 indoor units. In fact, dozens of indoor units can be installed on the outdoor unit, whose system principle is the same as that in Fig. 1. 


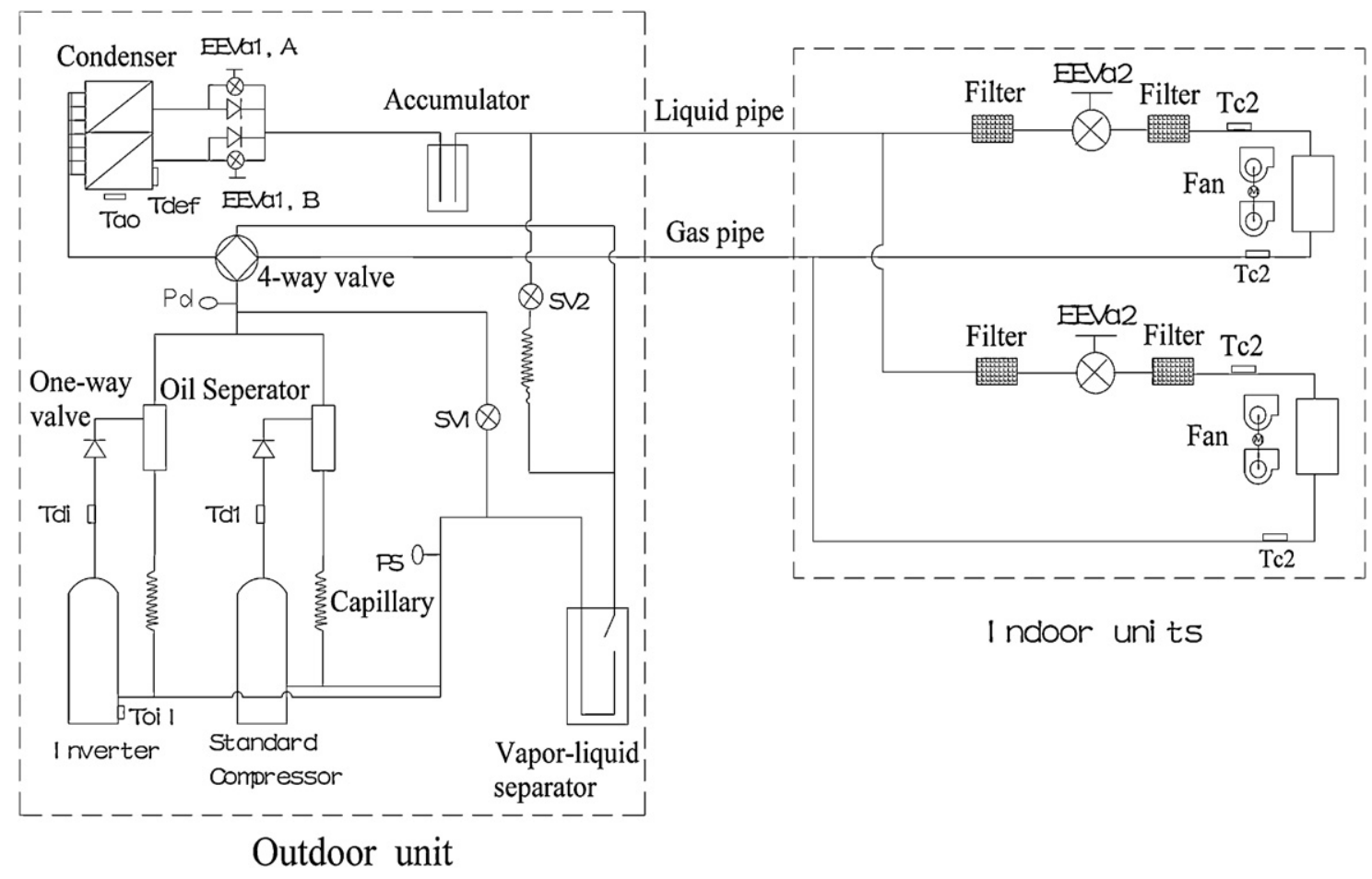

Fig. 1. Principle diagram of VRF AC.

In Fig. $1, T_{\mathrm{di}}, T_{\mathrm{d} 1}, T_{\mathrm{oil}}, T_{\mathrm{ao}}, T_{\mathrm{def}}, T_{\mathrm{C} 1}, T_{\mathrm{C} 2}$ are respectively discharge temperatures of the inverter-driven compressor and standard compressor, compressor oil temperature, ambient temperature, coil temperature, temperature in the gas pipe and throttled temperature in the liquid pipe of the indoor unit, which are measured by the corresponding temperature sensors. The coil temperature sensor is located at the end of the bottom coil because the coil temperature is the lowest. It has been verified by the experiments. $P_{\mathrm{d}}, P_{\mathrm{s}}$ are respectively discharge pressure and suction pressure measured by the pressure sensors. EEVa1,A and EEVa1,B respectively mean EEVs in the outdoor unit, and EEVa2 denotes EEV in the indoor unit. SV1 and SV2 are respectively solenoid valves for balance between $P_{\mathrm{d}}$ and $P_{\mathrm{S}}$ in order to reduce load when the compressors start, and for injection of liquid refrigerant to prevent overheating.

\section{Experimental setup}

In order to validate whether the criterion model of time-coil temperature can be feasibly used in VRF AC, a set of VRF AC experimental setup, shown in Fig. 2, was adopted to make heating experiment.

The type of the VRF AC is KMR-450W/D532B, whose capacity is $45 \mathrm{~kW}$. The system was charged with $16 \mathrm{~kg}$ refrigerant, R410A. Two EEVs (HAM-BD24FKS) were utilized in the outdoor unit to control the discharge superheated degree in heating mode. Five indoor units were installed in the VRF AC, whose types are shown in Fig. 2.

The experiment was made in the enthalpy difference lab of Haier Air-Conditioning Electronic Co. LTD. The self-made monitoring software was adopted to record the operation parameters, such as $T_{\mathrm{ao}}, T_{\mathrm{di}}, T_{\mathrm{d} 1}, T_{\mathrm{oil}}, T_{\mathrm{def}}, P_{\mathrm{d}}$ and corresponding saturation temperatures $\left(P_{\mathrm{d}_{-} \mathrm{t}}\right.$, i.e., condensation temperature $), P_{\mathrm{S}}$, operation frequency (INV_F), opening of EEVa1 in the outdoor unit (LEVa1), and monitor running status of components, for instance, on-off status of fan in the outdoor unit, four-way valve and solenoid valves. In Fig. 2, E/M, $\mathrm{N}, \mathrm{Q}$ respectively means medium static pressure duct indoor unit, low static pressure duct indoor unit and 4-way cassette indoor unit, and 22,112 respectively denotes the capacity of the indoor unit, $2.2 \mathrm{~kW}$ and $11.2 \mathrm{~kW}$.

\subsection{Experimental results and analysis}

The ambient temperatures of the outdoor chamber and indoor chamber were adjusted to be $7^{\circ} \mathrm{CDB} / 6^{\circ} \mathrm{CWB}$, and $20^{\circ} \mathrm{CDB} / 15^{\circ} \mathrm{CWB}$, respectively. The heating experiment was made under the control program of time-coil temperature determination criterion. In detail, the control program began to judge the coil temperature after the machine ran for $60 \mathrm{~min}$ by the end of last defrosting, and then the machine began to defrost by reverse-cycle defrosting style when the coil temperature was less than $-4^{\circ} \mathrm{C}$. In monitored curves, LEVa1,A of only one EEVa1 was given because of the same opening of EEVa1,A as that of EEVa1,B.

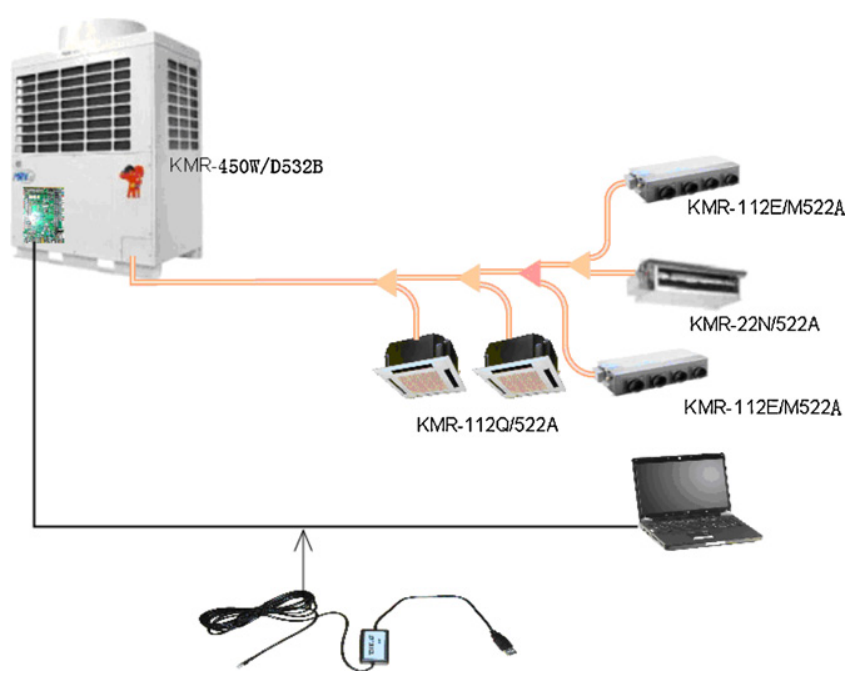

Fig. 2. Equipment diagram of VRF AC. 


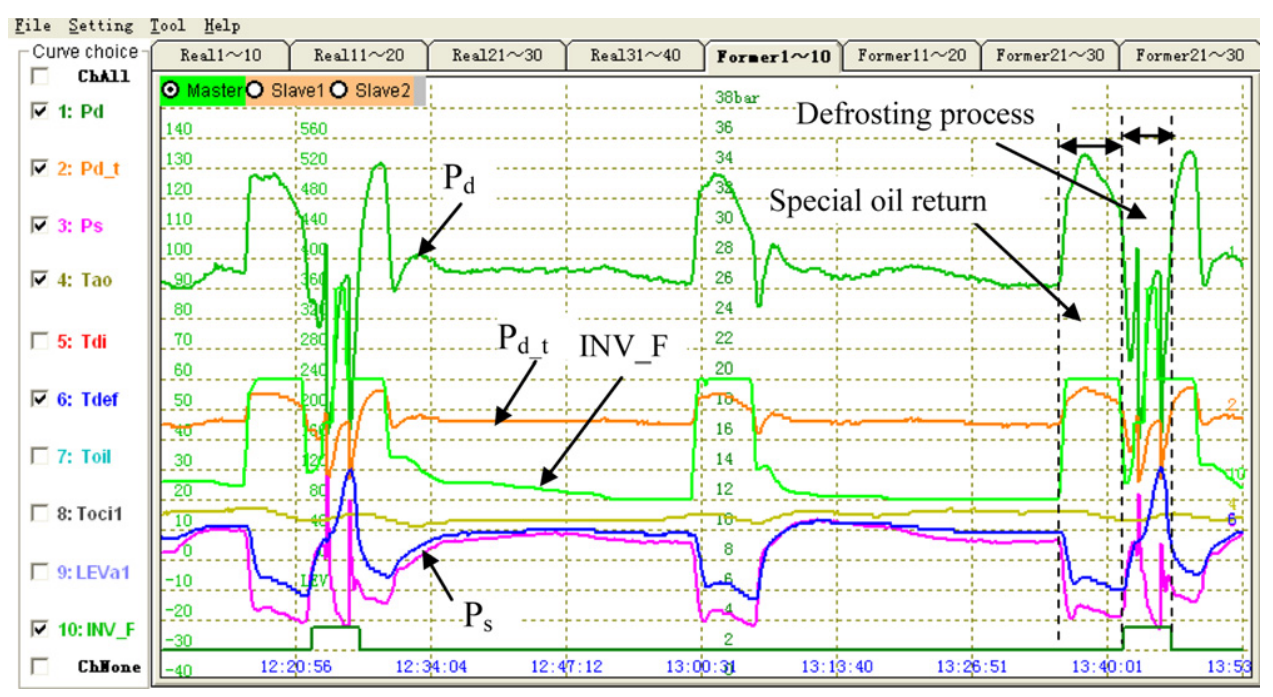

Fig. 3. Experimental result of false defrosting in nominal heating.

Experimental results show that when all of the indoor units were in heating motion, the defrosting determination criterion was feasible, and defrosting process occurred every about $90 \mathrm{~min}$. During the process of heating operation, condensation temperature decreased from $46^{\circ} \mathrm{C}$ to $33^{\circ} \mathrm{C}$, the average air outlet temperature dropped from $42^{\circ} \mathrm{C}$ to $31^{\circ} \mathrm{C}$, and the heat exchanger was covered with frost layer, and then defrosting began.

However, when the small indoor unit (KMR-22N/522A) was turned on in heating mode and other indoor units were thermo-off, the phenomenon of false defrosting occurred. In fact, no frost was accumulated around the heat exchanger surface. The experimental results are shown in Fig. 3.

In Fig. 3, there was a special oil return process lasting $5 \mathrm{~min}$ during the process of the nominal heating experiment. The purpose is, due to poor effect of oil return when INV_F is lower than $60 \mathrm{~Hz}$, to increase INV_F up to $60 \mathrm{~Hz}$ to accomplish the compressor oil return process for 5 min every 30 min to prevent the compressor lacking oil.

Fig. 3 illustrates that when the determination criterion of the defrosting condition was met, the discharge pressure was 26 bar and the condensation temperature was $44^{\circ} \mathrm{C}$, which indicates that the air outlet temperature could be kept at $41^{\circ} \mathrm{C}$. However, no frost was formed around the heat exchanger surface. Obviously, the determination criterion of defrosting condition was not accurate, and could not be used in VRF AC. The reason that the false defrosting occurred can be explained as below. The output capacity of the compressor was so small when only the small indoor unit was in heating motion that the running frequency of the inverter-driven compressor was minimal, i.e., $20 \mathrm{~Hz}$, and standard compressor stopped. However, during the process of special oil return, the frequency increased from $20 \mathrm{~Hz}$ up to $60 \mathrm{~Hz}$, and suction pressure decreased from 9.2 bar down to 5.0 bar, subsequently, the coil temperature quickly dropped below $-4{ }^{\circ} \mathrm{C}$, and defrosting condition was achieved.

And then, the defrosting judgment temperature was revised to be $-6^{\circ} \mathrm{C}$ in the control program. The phenomenon of false defrosting occurred again.

So, the experiment demonstrates that the time-coil temperature criterion model has obvious defects to lead to false defrosting, and is not feasible for VRF AC.

\subsection{Determination criterion model of defrosting condition}

For VRF AC, due to the fact that the wet bulb temperature and relative humidity cannot be measured in practical application, the defrosting criterion can be only determined by coil dry bulb temperature under different ambient temperatures. Taking into account the actual situation, it is assumed to divide the temperature range into four intervals: $T_{\mathrm{ao}} \in\left(-\infty, T_{\mathrm{ao}, \mathrm{C}}\right], T_{\mathrm{ao}} \in\left(T_{\mathrm{ao}, \mathrm{C}}, 0\right], T_{\mathrm{ao}} \in(0$, $\left.T_{\mathrm{ao}, \mathrm{B}}\right]$ and $T_{\mathrm{ao}} \in\left(T_{\mathrm{ao}, \mathrm{B}}, T_{\mathrm{ao}, \mathrm{A}}\right]$. Within the ambient temperature range, the defrosting determination model is depicted in Fig. 4.

Assuming that coordinates of Point $\mathrm{B}$ and Point $\mathrm{O}$ in Fig. 4 are respectively $\left(T_{\mathrm{ao}, \mathrm{B}}, T_{\mathrm{def}, \mathrm{AB}}\right)$ and $\left(0, T_{\mathrm{def}, \mathrm{O}}\right)$. The relation between the defrosting judgment temperature $T_{\mathrm{def}, \mathrm{BO}}$ and ambient temperature $T_{\mathrm{ao}}, T_{\mathrm{ao}} \in\left(0, T_{\mathrm{ao}, \mathrm{B}}\right]$ can be written as

$\frac{T_{\text {def,BO }}-T_{\text {def,AB }}}{T_{\text {def, } \mathrm{O}}-T_{\text {def,AB }}}=\frac{T_{\mathrm{ao}, \mathrm{BO}}-T_{\mathrm{ao}, \mathrm{B}}}{0-T_{\mathrm{ao}, \mathrm{B}}}$

According to Eq. (1), the expression of $T_{\text {def,Bo }}$ can be calculated as

$T_{\mathrm{def}, \mathrm{BO}}=\frac{T_{\mathrm{ao}, \mathrm{BO}} *\left(T_{\mathrm{def}, \mathrm{AB}}-T_{\mathrm{def}, \mathrm{O}}\right)}{T_{\mathrm{ao}, \mathrm{B}}}+T_{\mathrm{def}, \mathrm{O}}$

Similarly, the expression of $T_{\mathrm{def}, \mathrm{CO}\left(\mathrm{B}^{\prime}\right)}$ can be obtained as

$T_{\mathrm{def}, \mathrm{CO}\left(\mathrm{B}^{\prime}\right)}=\frac{T_{\mathrm{ao}, \mathrm{OC}} *\left(T_{\mathrm{def}, \mathrm{CD}}-T_{\mathrm{def}, \mathrm{O}}\right)}{T_{\mathrm{ao}, \mathrm{C}}}+T_{\mathrm{def}, \mathrm{O}}$

The defrosting criterion model can be built as below.

Once one or two compressors begin to be operated, the running time of the compressors is recorded by the calculagraph. And it

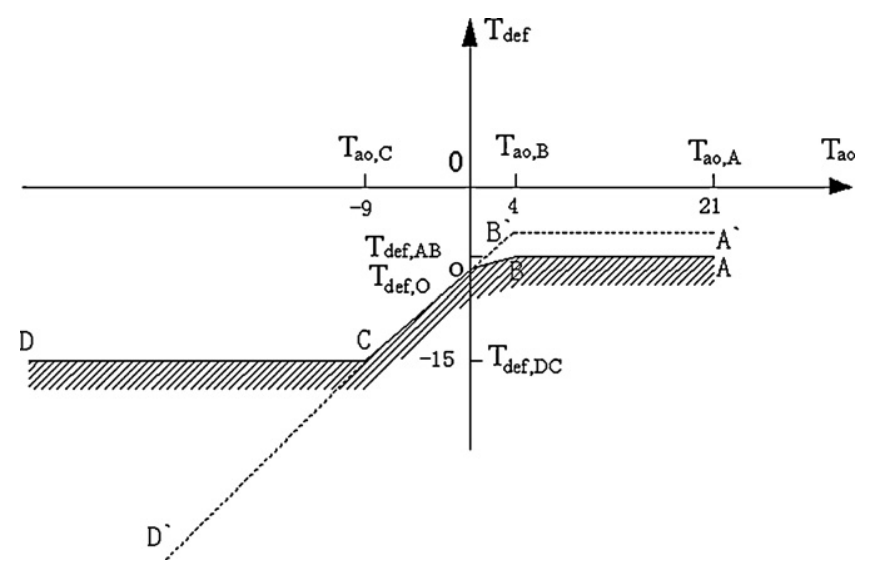

Fig. 4. Diagram of the criterion model of defrosting condition among different ambient temperatures. 
resets when the defrosting process starts to be executed. Then it restarts after the defrosting process is finished.

In order to avoid false defrosting and premature defrosting, and guarantee normal running, a minimum defrosting cycle must be defined in the criterion model, which is determined by experiment.

$$
\underbrace{t_{\mathrm{r}, \mathrm{AB}}+t_{\mathrm{r}, \mathrm{BO}}+t_{\mathrm{r}, \mathrm{OC}}+t_{\mathrm{r}, \mathrm{CD}}}=t_{\mathrm{min}}+\Delta t_{\mathrm{r}, \mathrm{CD}} * \operatorname{sgn}\left(t_{\mathrm{r}, \mathrm{CD}}\right)
$$

between two defrosting

Here $\operatorname{sgn}\left(t_{\mathrm{r}, \mathrm{CD}}\right)= \begin{cases}1 & t_{\mathrm{r}, \mathrm{CD}}>0 \\ 0 & t_{\mathrm{r}, \mathrm{CD}}>0\end{cases}$

In Eq. (4), $t_{\mathrm{r}, \mathrm{AB}} t_{\mathrm{r}, \mathrm{BO}}, t_{\mathrm{r}, \mathrm{OC}}$ and $t_{\mathrm{r}, \mathrm{CD}}$ are respectively running time of the compressor between two defrosting among four ambient temperature regions, respectively. And $t_{\min }$ is the minimal defrosting cycle when $T_{\mathrm{ao}} \in\left(T_{\mathrm{ao}, \mathrm{C}}, T_{\mathrm{ao}, \mathrm{A}}\right] ; \Delta t_{\mathrm{r}, \mathrm{CD}}$ and $t_{\mathrm{min}}+\Delta t_{\mathrm{r}, \mathrm{CD}}$ are the extended running time of the compressor and the minimal defrosting cycle when $T_{\mathrm{ao}} \in\left(-\infty, T_{\mathrm{ao}, \mathrm{c}}\right]$, respectively.

Under the premise of satisfying Eq. (4), the control program begins to judge the coil temperature. When the coil temperature can satisfy Eq. (5), the second calculagraph begins to record the running time of the compressor, which is defined as the defrosting judgment time. The judgment time must satisfy the condition of the defrosting cumulative coefficient $f$, shown in Eq. (6). Or else, the second calculagraph resets. And then when Eq. (5) can be met again, it resumes recording the defrosting judgment time and defrosting cumulative coefficient begins to be added.

$$
\begin{gathered}
\left(\left(T_{\mathrm{ao}, \mathrm{B}}<T_{\mathrm{ao}} \leq T_{\mathrm{ao}, \mathrm{A}}\right) \cap\left(T_{\mathrm{def}}<T_{\mathrm{def}, \mathrm{AB}}\right)\right) \cup\left(\left(0<T_{\mathrm{aoo}} \leq T_{\mathrm{ao}, \mathrm{B}}\right)\right. \\
\left.\cap\left(T_{\mathrm{def}}<T_{\mathrm{def}, \mathrm{OB}}\right)\right) \cup\left(\left(T_{\mathrm{ao}, \mathrm{C}}<T_{\mathrm{ao}} \leq 0\right) \cap\left(T_{\mathrm{def}}<T_{\mathrm{def}, \mathrm{OC}}\right)\right) \\
\cup\left(\left(T_{\mathrm{ao}} \leq T_{\mathrm{ao}, \mathrm{C}}\right) \cap\left(T_{\mathrm{def}}<T_{\mathrm{def}, \mathrm{CD}}\right)\right)=\text { "true" } \\
f=\frac{t_{\mathrm{d}, \mathrm{AB}}+t_{\mathrm{d}, \mathrm{BO}}+t_{\mathrm{d}, \mathrm{OC}}+t_{\mathrm{d}, \mathrm{CD}}}{t_{\mathrm{con}}}=1
\end{gathered}
$$

Here, $t_{\mathrm{d}, \mathrm{AB}}, t_{\mathrm{d}, \mathrm{BO}}, t_{\mathrm{d}, \mathrm{OC}}$ and $t_{\mathrm{d}, \mathrm{CD}}$ are defrosting judgment time respectively under the premise of satisfying Eq. (4) as well as $\left(\left(T_{\mathrm{ao}, \mathrm{B}}<T_{\mathrm{ao}} \leq T_{\mathrm{ao}, \mathrm{A}}\right) \cap\left(T_{\mathrm{def}}<T_{\mathrm{def}, \mathrm{AB}}\right)\right)$ $\left(\left(0<T_{\mathrm{ao}} \leq T_{\mathrm{ao}, \mathrm{B}}\right) \cap\left(T_{\text {def }}<T_{\text {def,OB }}\right)\right), \quad\left(\left(T_{\mathrm{ao}, \mathrm{C}}<T_{\mathrm{ao}} \leq 0\right) \cap\left(T_{\mathrm{def}}<T_{\text {def,OC }}\right)\right)$ and $\left(\left(T_{\mathrm{ao}} \leq T_{\mathrm{ao}, \mathrm{C}}\right) \cap\left(T_{\mathrm{def}}<T_{\mathrm{def}, \mathrm{CD}}\right)\right)$. And $t_{\mathrm{con}}$ is a certain defrosting criterion time constant under the promise of satisfying Eqs. (4) and (5), which is determined by experiment to be $5 \mathrm{~min}$, shown in Section 4.2.4.

From the above analysis, in order to avoid premature defrosting and false defrosting, the condensation temperature restriction must be added to the criterion model, i.e.

$T_{\mathrm{c}, \mathrm{c}}<T_{\mathrm{c}, \mathrm{tar}}-12$

Here, $T_{\mathrm{c}, \operatorname{tar}}$ and $T_{\mathrm{c}, \mathrm{c}}$ are respectively condensation temperature target, $46^{\circ} \mathrm{C}$, and current condensation temperature reflecting the actual operational capacity of the compressors.

Eqs. (4)-(7) constitute the criterion model of defrosting condition for VRF AC. In the complete model, the fluctuations of ambient temperature and coil temperature are taken into account due to all kinds of factors such as ambient temperature change, resistance drift of coil temperature sensor, opening regulation of EEV or required load change of indoor units, etc.

\section{Experiment}

\subsection{Experimental procedure}

Firstly, the parameters in the model, such as $T_{\text {def,AB }}, T_{\text {def,CD }}$, $T_{\mathrm{def}, \mathrm{O}}, t_{\mathrm{min}}, \Delta t_{\mathrm{r}, \mathrm{CD}}$ and $t_{\mathrm{con}}$ were determined by experiment. Among these parameters, $t_{\mathrm{min}}$ and $\Delta t_{\mathrm{r}, \mathrm{CD}}$ were obtained above $0{ }^{\circ} \mathrm{C}$ ambient temperature with the humidity as large as possible, and $-15^{\circ} \mathrm{C} \mathrm{DB} /-10^{\circ} \mathrm{C} \mathrm{WB}$ ambient temperature, respectively. And then, the relations between the defrosting judgment temperature and ambient temperature were ascertained by experiments in the corresponding ambient temperature regions. Moreover, $t_{\text {con }}$ was determined under the condition of the coil temperature oscillation, which was operated by adjusting the opening of EEV. The experimental method to ascertain these parameters was that when the heat exchanger surface was accumulated with frost layer, the current condensation temperature was less than $34^{\circ} \mathrm{C}$, and average air outlet temperature was below $31^{\circ} \mathrm{C}$, the signal "Defrost" was transmitted from the wired controller connected with the indoor units to remove the frost layer. Thus the parameters can be determined from the collected experimental curves.

After the parameters were determined by experiment, they were set in the control program. Finally, the experiments were made under different ambient temperatures to validate the feasibility of the built model.

\subsection{Determination of parameters}

\subsubsection{Determination of $T_{a o, A}, T_{a o, B}$ and $T_{a o, C}$}

It is well known that the frost layer is most likely formed among the ambient temperature region, $-10-5{ }^{\circ} \mathrm{C}$, and the temperature region is the most extensive application range of VRF AC. However, when the ambient temperature is below $-10^{\circ} \mathrm{C}$, vapor in the air will be condensed into water to result in lower air humidity. Even if the outdoor heat exchanger frosts, the frost layer is very thin. Thus $T_{\mathrm{ao}, \mathrm{A}}, T_{\mathrm{ao}, \mathrm{B}}$ and $T_{\mathrm{ao}, \mathrm{C}}$ are empirically determined to be $-9^{\circ} \mathrm{C}$, $4{ }^{\circ} \mathrm{C}, 21^{\circ} \mathrm{C}$, respectively.

\subsubsection{Determination of minimum defrosting cycle $t_{\text {min }}$}

According to the analysis of the influence of the temperature on the characteristics of the frosting, the frost layer is formed quickest and heaviest under the condition of ambient temperature higher than $0^{\circ} \mathrm{C}$ with the largest humidity. Taking into account permissive laboratory condition, the relative humidity as large as possible can be adjusted to $95 \%$. Thus the large humidity heating experiment was made under the condition of $1^{\circ} \mathrm{C} \mathrm{DB} / 0.7^{\circ} \mathrm{C} \mathrm{WB}$ in the outdoor chamber and $20^{\circ} \mathrm{C} \mathrm{DB} / 15^{\circ} \mathrm{C} \mathrm{WB}$ in the indoor chamber. According to the above experimental method, when the frosting condition was satisfied, the code "Defrost" was sent out from the wired controller to remove the frost layer compulsively. The collected experimental curves are shown in Fig. 5.

The experiment was made for five defrosting cycles under the above condition. It can be seen from Fig. 5 that the average defrosting cycle was $68 \mathrm{~min}$. In order to timely and effectively remove all of the frost from the heat exchanger, the minimum defrosting cycle in the control program should be slightly less than $68 \mathrm{~min}$. So it was appropriate to determine the minimum defrosting cycle to be $60 \mathrm{~min}$.

\subsubsection{Determination of $\Delta t_{r, C D\left(D^{\prime}\right)}$ and $T_{d e f, C D}$}

As the above analysis, when the ambient temperature reduced to below $-10^{\circ} \mathrm{C}$, it will take a long time for the machine to form the frost layer. The minimum defrosting cycle will be extended to be a certain time, which is determined by experiment.

The experiment was made under the condition of $-15^{\circ} \mathrm{C}$ $\mathrm{DB} /-20^{\circ} \mathrm{CWB}$ in the outdoor chamber and $20^{\circ} \mathrm{CDB} / 15^{\circ} \mathrm{CWB}$ in the indoor chamber, respectively. The experimental results are shown in Fig. 6.

Numerous long-term running experiments show that the coil temperature did not reduce persistently with the experimental process, but basically remained at $-15^{\circ} \mathrm{C}$. The heat exchanger was covered with little thick frost when the machine ran for about $95 \mathrm{~min}$ after the end of last defrosting, and the defrosting determination criterion was met. So the minimum defrosting cycle and the 


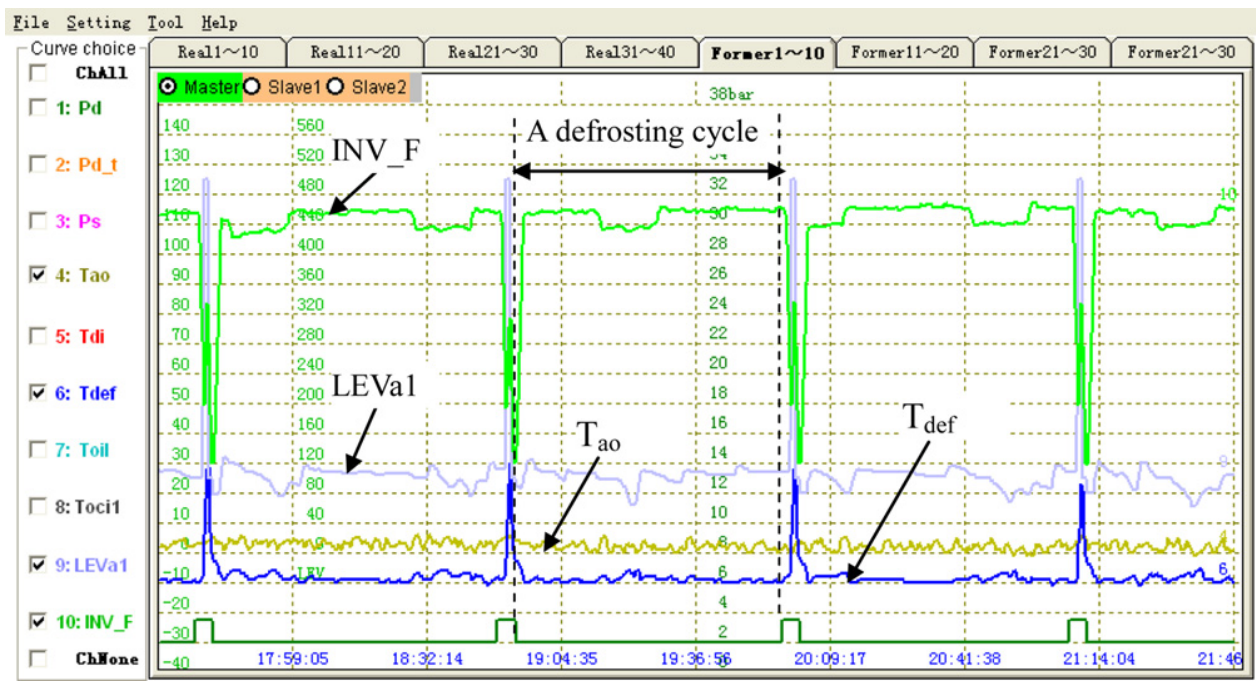

Fig. 5. Experimental results of large humidity defrosting.

defrosting judgment temperature $T_{\text {def,CD }}$ were respectively ascertained to be $90 \mathrm{~min}$ and $-15^{\circ} \mathrm{C}$. And heating experiments made under different ambient temperatures below $-9^{\circ} \mathrm{C}$, such as $-12^{\circ} \mathrm{C}$, $-15^{\circ} \mathrm{C}$, demonstrate that the minimum defrosting cycle is appropriate for VRF AC. From the analysis, it can be seen that the criterion model should not be carried out in accordance with Line $\mathrm{CD}^{\prime}$, but Line CD, in Fig. 4.

\subsubsection{Determination of defrosting criterion time constant $t_{c o n}$}

In the model of defrosting criterion, $t_{\text {con }}$ is critical for defrosting determination. If the value is set little longer, such as more than $20 \mathrm{~min}$, defrosting may not be carried out due to coil temperature oscillation caused by resistance drift of the temperature sensor, suction pressure fluctuation or opening regulation of EEV. On the contrary, if the value is set too short, frequent defrosting or premature defrosting may take place.

In order to demonstrate the influence of coil temperature oscillation on the determination criterion of defrosting condition, the opening of EEV was adjusted variably in the control program to make the coil temperature fluctuate. In detail, the control measure was that when the heating operation had been carried out for $30 \mathrm{~min}$ after the end of last defrosting, the opening of EEV began to oscillate at 50 PLS every $3 \mathrm{~min}$. The experiment was made under the condition of nominal heating, i.e., $7^{\circ} \mathrm{C} \mathrm{DB} / 6^{\circ} \mathrm{C} \mathrm{WB}$ in the outdoor chamber and $20^{\circ} \mathrm{C} \mathrm{DB} / 15^{\circ} \mathrm{C} \mathrm{WB}$ in the indoor chamber. The experimental results are shown in Fig. 7.

From Fig. 7 it can be seen that the opening oscillation of EEV can make great influence on the suction pressure and the coil temperature thereby. When the opening of EEV(LEVa1) increased from 50 PLS to 90 PLS in $3 \mathrm{~min}$, the suction pressure lifted from $3.6 \mathrm{bar}$ to $4.9 \mathrm{bar}$, subsequently, the coil temperature increased from $-9{ }^{\circ} \mathrm{C}$ to $-2{ }^{\circ} \mathrm{C}$. In contrast, when the opening of EEV decreased, the suction pressure and the coil temperature degraded, and the reduced amplitude of the coil temperature reached $7-8^{\circ} \mathrm{C}$ in $3 \mathrm{~min}$.

Analysis of the experimental results shows that if $t_{\text {con }}$ was set too long, once the oscillation of the coil temperature caused by any one factor took place, it would be so difficult or even impossible to satisfy Eqs. (5) and (6) in the criterion model of the defrosting condition that the defrosting would not almost be carried out. In accordance with practical situation, it is appropriate to determine the defrosting judgment time to be $5 \mathrm{~min}$ in the criterion model.

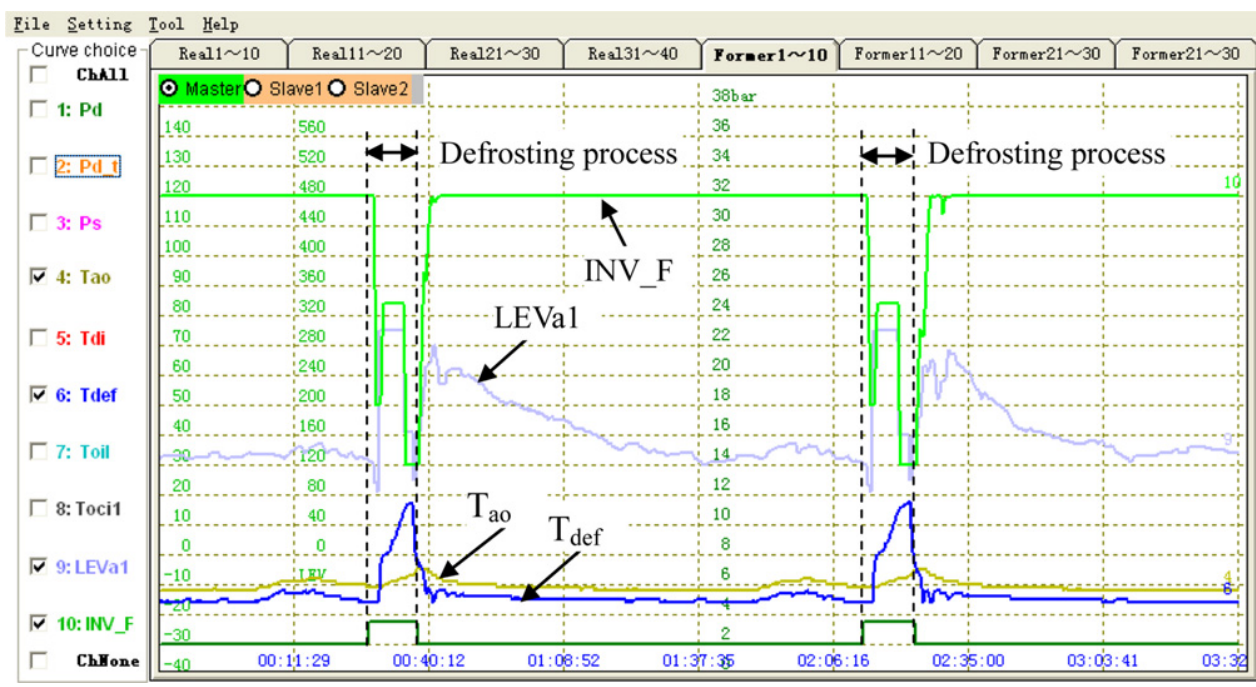

Fig. 6. Experimental results of low temperature heating at $T_{\mathrm{ao}}=-15^{\circ} \mathrm{CDB} /-20^{\circ} \mathrm{CWB}$. 


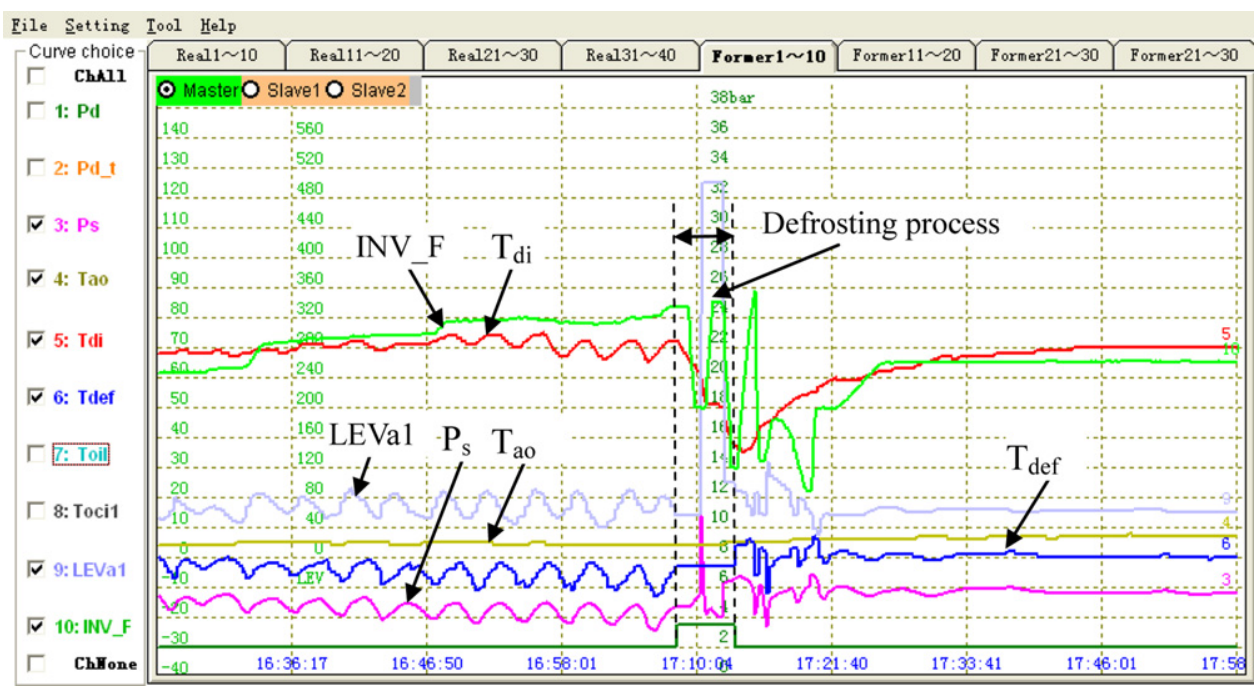

Fig. 7. Experimental results of coil temperature oscillation.

\subsubsection{Determination of $T_{\text {def,o }}$ and $T_{d e f, A B}$}

In order to determine $T_{\text {def }, o}$, the ambient temperatures of the outdoor chamber and indoor chamber were respectively adjusted to be $0^{\circ} \mathrm{C}$ DB with relative humidity $80 \%$, and $20^{\circ} \mathrm{C} \mathrm{DB} / 15^{\circ} \mathrm{C} \mathrm{WB}$ to make heating experiment.

With the ongoing of the heating experiment, more and more frost was produced, and condensation temperature reduced, subsequently the air outlet temperature from the indoor units dropped. When the condensation temperature dropped below $34^{\circ} \mathrm{C}$, the heat exchanger began to be covered with thick frost layer. By the same method, the experimental results were recorded, shown in Fig. 8.

Fig. 8 shows that the discharge pressure and condensation temperature gradually decreased when frost was formed, and the coil temperature oscillated from -5 to $7^{\circ} \mathrm{C}$. Finally, it was kept at $-7^{\circ} \mathrm{C}$ basically. Thus the defrosting judgment temperature $T_{\text {def,o }}$ was determined to be $-7^{\circ} \mathrm{C}$ when the ambient temperature was $0{ }^{\circ} \mathrm{C}$.

Fig. 8 also confirms that it is critical to introduce the defrosting cumulative coefficient into the defrosting criterion model. Or else, without the restriction of this coefficient, the coil temperature fluctuation will result in the premature defrosting. Furthermore, even if the cumulative coefficient is added to the defrosting criterion model, inaccessible defrosting will happen if the value of the coefficient is set larger.

In Fig. 4 , according to the linear relation, $T_{\text {def, } A^{\prime} B^{\prime}}$ was calculated to be $-4{ }^{\circ} \mathrm{C}$ among the ambient temperature range, $T_{\mathrm{ao}} \in\left(T_{\mathrm{ao}, \mathrm{B}}\right.$, $\left.T_{\mathrm{ao}, \mathrm{A}}\right]$.

In order to determine $T_{\mathrm{def}, \mathrm{AB}}$, the ambient temperatures of the outdoor chamber and indoor chamber were adjusted to be $7^{\circ} \mathrm{C}$ $\mathrm{DB} / 6^{\circ} \mathrm{CWB}$ and $20^{\circ} \mathrm{C} \mathrm{DB} / 15^{\circ} \mathrm{C}$ to make validation experiment. The experimental results of 6 defrosting cycles are shown in Fig. 9.

It can be seen from Fig. 9 that defrosting was carried out every about $60 \mathrm{~min}$. But in fact, when the defrosting condition was reached, the discharge pressure and condensation temperature remained basically unchanged, and almost no frost was formed around the heat exchanger surface, shown in Fig. 10.

Analysis of above experimental results shows that in the region of ambient temperature, $T_{\mathrm{ao}} \in\left(T_{\mathrm{ao}, \mathrm{B}}, T_{\mathrm{ao}, \mathrm{A}} \mathrm{]}\right.$, the defrosting judgment temperature $-4{ }^{\circ} \mathrm{C}$ leads to premature defrosting or false defrosting. Thus, it is unnecessary to continue heating experiment under other ambient temperatures.

So the set value of defrosting judgment coil temperature in the defrosting criterion model should be revised by experiment. After

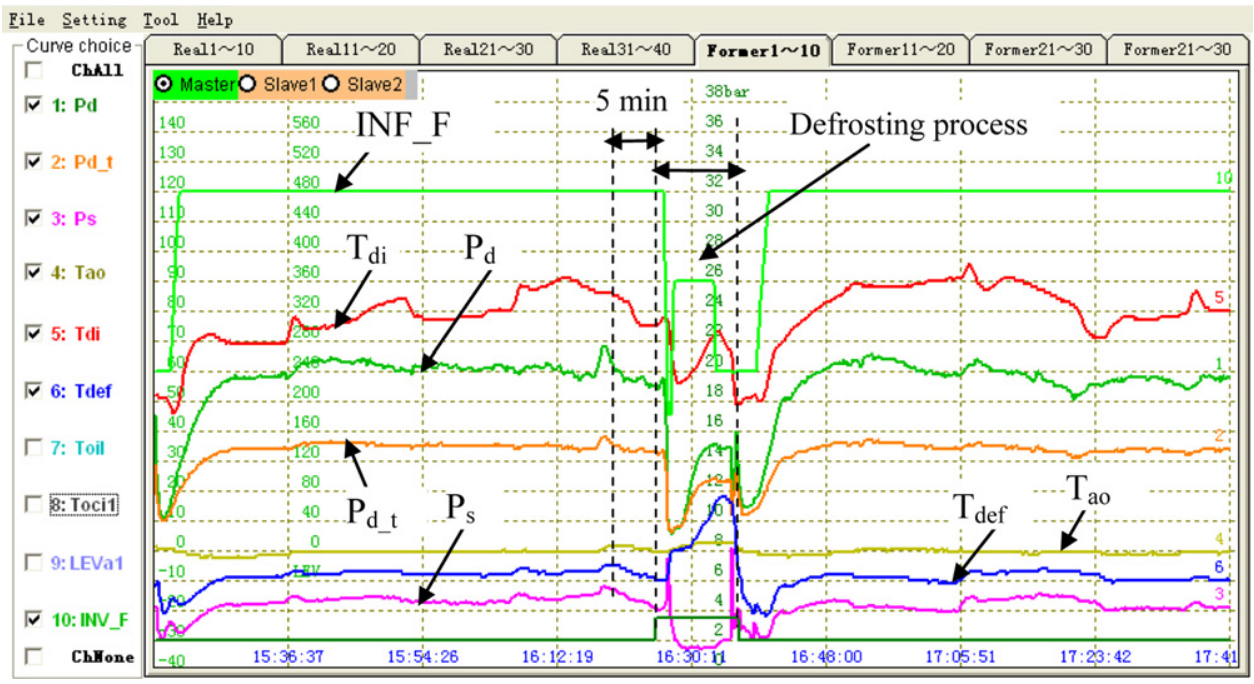

Fig. 8. Experimental results of heating under the condition of $0{ }^{\circ} \mathrm{C} D B$ with relative humidity $80 \%$ in the outdoor chamber. 


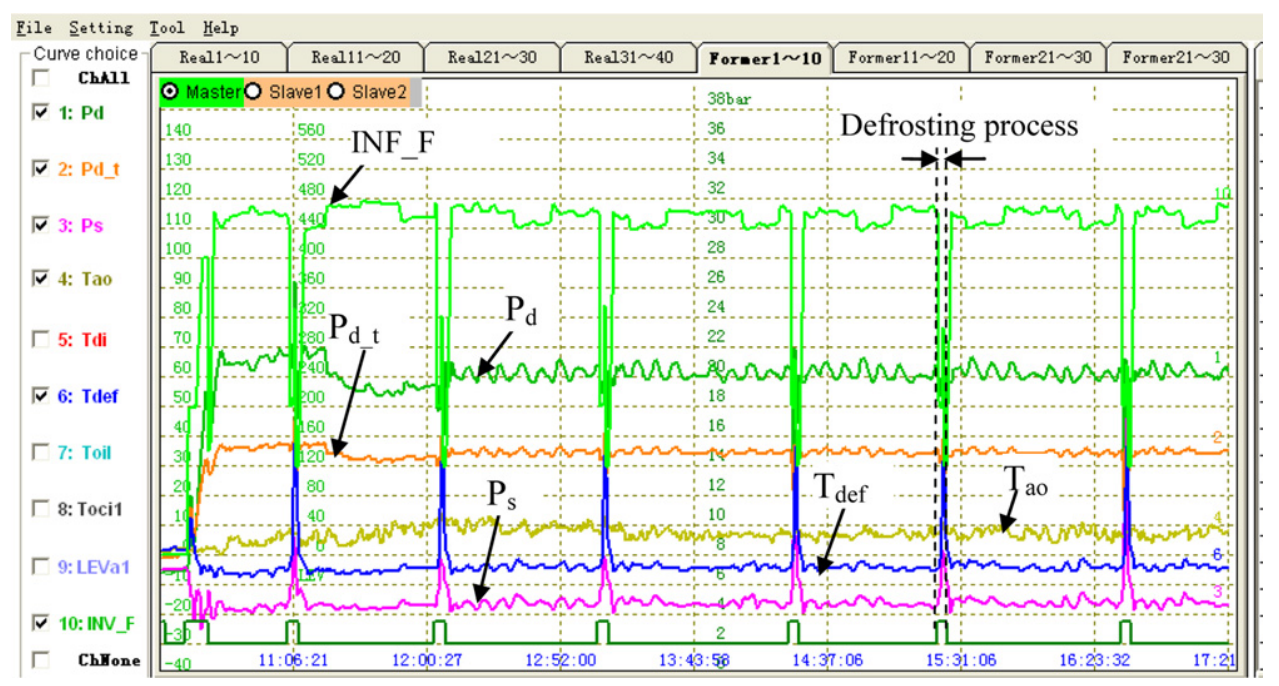

Fig. 9. Experimental results of nominal heating at $T_{\text {def,AB }}=-4^{\circ} \mathrm{C}$.

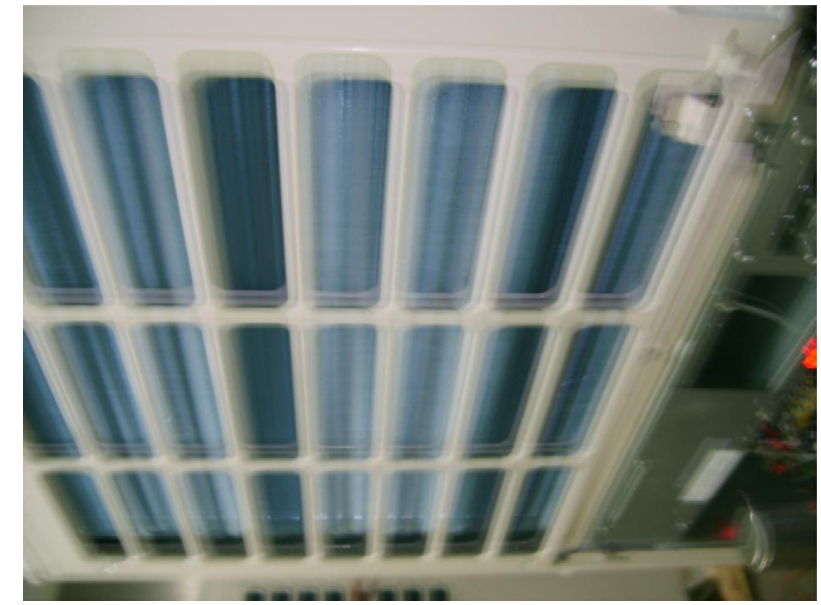

Fig. 10. A photo of no frost on the heat exchanger surface in the nominal heating experiment. the defrosting judgment temperature was revised as $-6^{\circ} \mathrm{C}$ in the control program, the experimental results are shown in Fig. 11.

Fig. 11 shows that when the defrosting condition was satisfied, the condensation temperature reduced to about $32^{\circ} \mathrm{C}$, and frost layer was evenly formed on the surface of the heat exchanger. The experimental results demonstrate the determined defrosting temperature is suitable for the nominal heating.

\subsection{Further experimental validation}

After these parameters in the criterion model were determined by experiment and defined in the frosting control program, automatic defrosting can be carried out in accordance with the control program. Then heating experiments were made under different ambient conditions to validate these parameters.

According to Eq. (3), the coil frosting determination temperature was calculated to be $-13^{\circ} \mathrm{C}$ at $T_{\mathrm{ao}}=-7^{\circ} \mathrm{C}$. And the ambient temperatures of the outdoor chamber and indoor chamber were respectively adjusted to be $-7^{\circ} \mathrm{C} \mathrm{DB} /-8^{\circ} \mathrm{C}$ DB and $20^{\circ} \mathrm{C} \mathrm{DB} / 15^{\circ} \mathrm{C}$ $\mathrm{DB}$ to make heating experiment. The experimental results of two defrosting cycles are given in Fig. 12.

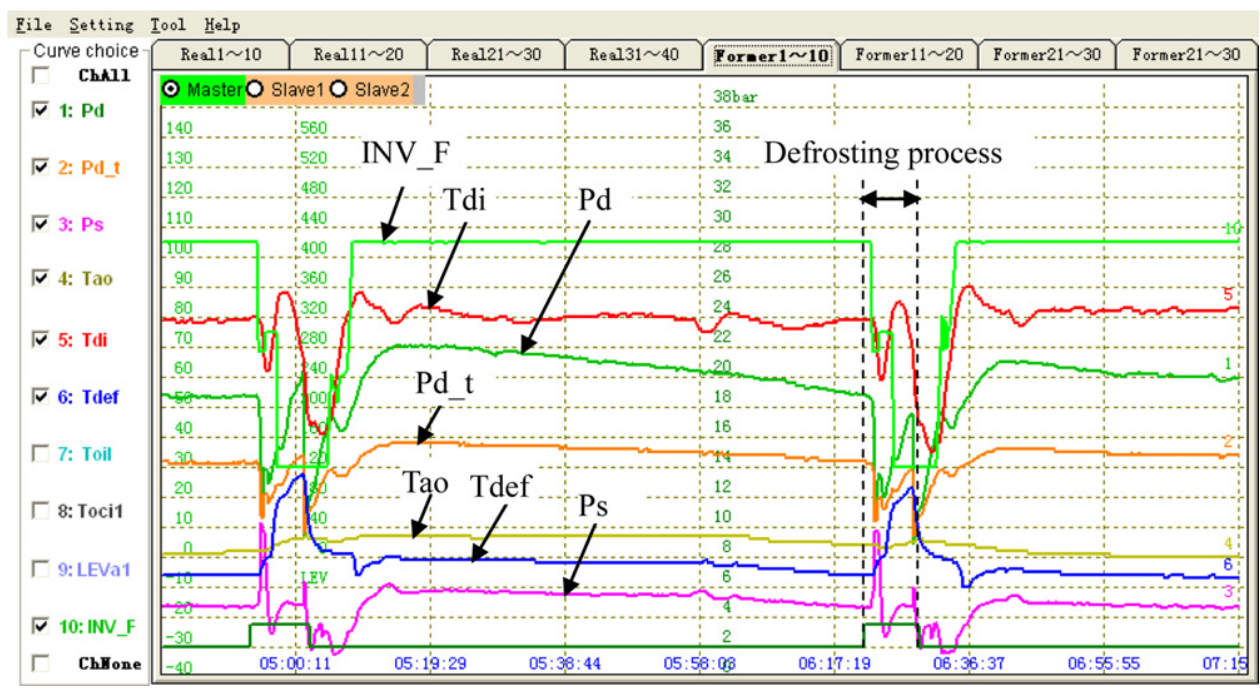

Fig. 11. Experimental results of nominal heating at $T_{\mathrm{def}, A B}=-6^{\circ} \mathrm{C}$. 


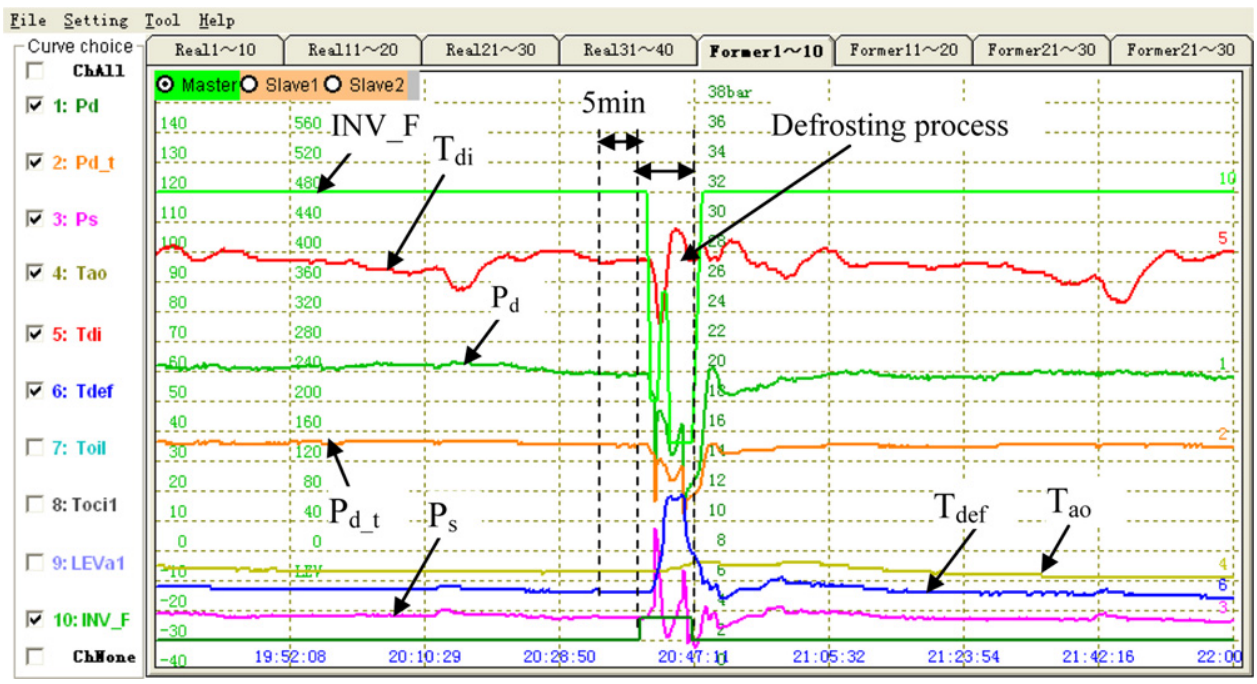

Fig. 12. Experimental results of low temperature heat experiment at $T_{\mathrm{ao}}=-7^{\circ} \mathrm{C} \mathrm{DB} /-8^{\circ} \mathrm{C} \mathrm{WB}$.

Fig. 12 shows that the frost was gradually accumulated on the heat exchanger surface, discharge pressure decreased form 22 bar to $20 \mathrm{bar}$, the condensation temperature dropped from $38^{\circ} \mathrm{C}$ to $34^{\circ} \mathrm{C}$, and the coil temperature reduced to $-13^{\circ} \mathrm{C}$. When the coil temperature was lower than $-13^{\circ} \mathrm{C}$ for $5 \mathrm{~min}$, defrosting cumulative coefficient reached 1, and then the defrosting process began. Experimental results demonstrate that the built determination criterion of defrosting condition is feasible when the ambient temperature of outdoor chamber is $-7^{\circ} \mathrm{C}$.

And then, heating experiments were made under the conditions of $T_{\mathrm{ao}}=-5^{\circ} \mathrm{C}$ and $-2{ }^{\circ} \mathrm{C}$ with relative humidity $80 \%$. And the experimental results demonstrate the feasibility of the model in the region of ambient temperature, $T_{\mathrm{ao}} \in\left(T_{\mathrm{ao}, \mathrm{C}}, 0\right]$.

Similarly, the heating experiments under the condition of $2^{\circ} \mathrm{C}$ $\mathrm{DB}, 5^{\circ} \mathrm{CDB}$ and $10^{\circ} \mathrm{C}$ with $85 \%$ relative humidity were made respectively. And the experiments show that the revised model is feasible for VRF AC when $T_{\mathrm{ao}} \in\left(0, T_{\mathrm{ao}, \mathrm{A}}\right]$. When the ambient temperature rises above $15^{\circ} \mathrm{C}$, a large number of experiments demonstrate that defrosting process does not occur. And there is no frost covered around the heat exchanger surface actually.

\section{Conclusion}

From this study, the following conclusion can be drawn.

Experiments have proved that the coil temperature is affected by many factors, in which the influence of the suction pressure on the coil temperature is the most obvious and direct. The coil temperature reduces to meet the defrosting condition when the suction pressure decreases. Thus the criterion model of time-coil temperature cannot be applied in VRF AC. Experiment also reveals disadvantage of the model. So it is necessary to add the restriction of the condensation temperature in the criterion model of defrosting condition.

The criterion model of defrosting condition of time-coil temperature-condensation temperature has been built. In the model, there exist four regions based on different frosting characteristics at different ambient temperatures, i.e., $T_{\mathrm{ao}}\left({ }^{\circ} \mathrm{C}\right) \in(-\infty$, -9], (-9, 0], (0, 4], (4, 21].

A minimum defrosting cycle defined in the criterion model can avoid false defrosting and premature defrosting, and guarantee normal heating operation and users reliable application of VRF AC. The heating experiment shows that when, with ongoing of heating experiment, the defrosting judgment temperature does not decrease persistently, but is kept almost at a certain temperature.
In this region, the minimum defrosting cycle was appropriately determined to be 90 min by experiment. And in other regions, the minimum defrosting cycle was determined to be $60 \mathrm{~min}$.

And the defrosting criterion time constant and accumulative coefficient defined in the criterion model can be used to prevent premature defrosting, delayed defrosting and inaccessible defrosting due to the oscillation of the coil temperature. If it is defined as a very short time in the control program, premature defrosting may be carried out. In contrast, a long criterion time may lead to delayed defrosting, and even inaccessible defrosting. Experiment reveals that it is reasonable to determine the defrosting judgment time to be 5 min.

A large number of experiments and practical engineering application demonstrate that the built criterion model is feasible for VRF AC. It can provide guide for the design and application of VRF AC.

\section{Acknowledgment}

The authors would like to thank the experimental support from Haier Air-Conditioning Electronic Co. LTD.

\section{References}

[1] D.L. O’Neal, K.T. Peterson, N.K. Anand, J.S. Schiliesing, Refrigeration system dynamics during the reverse cycle defrost, ASHRAE Transactions 95 (2) (1989) 689-698.

[2] D.L. O'Neal, K.T. Peterson, N.K. Anand, Effect of short-tube orifice size on the performance of an air source heat pump during the reverse-cycle defrost, International Journal of Refrigeration 14 (7) (1991) 52-57.

[3] D. Yanjun, M. Guoyuan, C. Qinhu, J. Yi, Experiment investigation of reverse cycle defrosting methods on air source heat pump with TXV as the throttle regulator, International Journal of Refrigeration 27 (6) (2004) 671-678.

[4] D. Huang, X. Yuan, X. Zhang, Effects of fan-starting methods on the reversecycle defrost performance of an air-to-water heat pump, International Journal of Refrigeration 27 (8) (2004) 869-875.

[5] D. Huang, Q. Li, X. Yuan, Comparison between hot-gas bypass defrosting and reverse-cycle defrosting methods on an air-to-water heat pump, Applied Energy 86 (2009) 1697-1703.

[6] E. Kuwahara, T. Kawamura, M. Yamazaki, Shorting the defrost time on a heat pump air conditioner, ASHRAE Transactions 92 (2A) (1985) 20-29.

[7] K.I. Krakow, L. Sui, Hot-gas bypass defrosting of evaporator utilizing a vaporizer, ASHRAE Transactions 102 (1) (1996) 385-394.

[8] W. Shi, X. Li, S. Shao, Experimental research on hot vapor bypass defrosting method, Journal of Refrigeration in China 2 (2000) 29-35.

[9] N. Hewitt, M.J. Huang, Defrost cycle performance for a circular shape evaporator air source heat pump, International Journal of Refrigeration 31 (3) (2008) 444-452.

[10] W. Zhiyi, W. Xinmin, D. Zhiming, Defrost improvement by heat pump refrigerant charge compensating, Applied Energy 85 (11) (2008) 1050-1059. 
[11] W. Fu, X. Guo, X. Tao, Experiment on a novel defrost cycle for air source heat pumps, Journal of Refrigeration in China 30 (3) (2009) 16-20.

[12] C. Ying, X. Li, Determination criterion of frost and defrost for heat pump air conditioners, Heating Ventilating \& Air Conditioning 31 (6) (2001) 44-46.

[13] F. Zheng, Z. Runqing, C. Jing, Experimental study on the optimal defrosting point of the constant temperature and humidity system, Refrigeration and AirConditioning in China 4 (2) (2004) 45-49.

[14] T.N. Aynur, Y. Hwang, R. Radermacher, Integration of variable refrigerant flow and heat pump desiccant systems for the heating season, Energy and Buildings $42(4)$ (2010) 468-476.
[15] T.N. Aynur, Variable refrigerant flow systems: a review, Energy and Buildings 42 (7) (2010) 1106-1112.

[16] Q. Tu, Z. Feng, S. Mao, K. Dong, R. Xiao, W. Song, Heating control strategy for variable refrigerant flow air conditioning system with multi-module outdoor units, Energy and Buildings 42 (11) (2010) 2021-2027.

[17] G. Zhujun, X. Wenbin, F. Bin, T. Liqiang, Research on a kind of defrosting control method - maximum average heating capacity, Refrigeration in China 26 (2) (2007) 14-17.

[18] J.-S. Byun, C.-D. Jeon, J.-H Jung, J. Lee, The application of photo-coupler for frost detecting in an air-source heat pump, International Journal of Refrigeration 29 (2006) 191-198. 